ELECTRONIC LETTER

\title{
Spontaneous recovery of a childhood onset mitochondrial myopathy caused by a stop mutation in the mitochondrial cytochrome c oxidase III gene
}

\author{
R Horváth, H Lochmüller, M Hoeltzenbein, J Müller-Höcker, B G Schoser D Pongratz, M Jaksch
}

J Med Genet 2004;41:e75 (http://www.jmedgenet.com/cgi/content/full/41/6/e75). doi: 10.1136/jmg.2003.015024

d n general, the clinical course of patients suffering from different types of mtDNA mediated neurodegenerative disorders progresses with age. ${ }^{1}$ The clinical progression of muscle weakness has been reported to correlate with an increase in cytochrome c oxidase (COX) negative fibres ${ }^{2}$ or with an increase of mutant mtDNA in skeletal muscle. ${ }^{3}$

In a recent issue we reported on a patient with mitochondrial myopathy with ragged red fibres (RRF), lactic acidosis, exercise intolerance, and delayed growth, with a heteroplasmic G9379A nonsense mutation (W58X) in the mtDNA encoded COIII subunit gene. ${ }^{4}$ A follow up examination of the patient showed significant improvement of the neurological symptoms. Here we present the results of detailed clinical, histological, immunohistological, biochemical, and genetic investigations of a repeated muscle biopsy, which all confirm a spontaneous regression of the disease.

\section{PATIENT AND METHODS Case report}

The early clinical history of the patient has been previously reported in detail ${ }^{4}$ and is now compared with recent examinations (table 1). In brief, he developed exercise intolerance, generalised muscle weakness with painful muscle cramps, and fatigue at the age of 6 years, and his symptoms were progressing. On examination at 14 years of age, his somatic growth was delayed and he presented generalised mild muscle weakness, muscular hypotonia, and scapular winging. Symptomatic therapy with L-carnitin $(2 \times 10 \mathrm{ml})$, sodium hydrogen carbonate, and regular physiotherapy were initiated.

From the age of 16 years the patient's symptoms improved gradually. At 19 years of age rapid growth was noted, but his weight remained low. A detailed neurological examination was carried out at his present age of 20 years. The patient reported an improvement in his muscle strength and the resolution of exercise intolerance. Episodes of myoglobinuria were never reported.

On examination mild scapular winging was noted. Muscle strength was $5 / 5$ in all muscle groups, except for a very mild weakness in the foot dorsiflectors (mild difficulty in walking on heels). Deep tendon reflexes were mildly decreased on both sides. In addition to his weekly physiotherapy he now performs some sport (cycling) and works full time.

\section{Morphology, immunohistochemistry, and biochemistry of skeletal muscle}

At 14 and 20 years of age, open muscle biopsies of the patient were performed. The first biopsy was from the right quadriceps femoris, the second from the right tibialis anterior muscle. Muscle sections of both biopsies were histochemically stained with ATPase at different $\mathrm{pH}$ according to standard procedures. ${ }^{56}$ A total of 515 fibres (first biopsy, vastus lateralis) and 528 fibres (second biopsy, tibialis

\section{Key points}

- In a recent issue we reported on a patient suffereing from mitochondrial myopathy with ragged red fibres, lactic acidosis, exercise intolerance, and delayed growth with a heteroplasmic G9379A nonsense mutation (W58X) in the mtDNA encoded COIII subunit gene.

- A follow up examination of the patient showed remarkable clinical and electrophysiological improvement.

- On a repeated muscle biopsy, signs of histological and immunohistological improvement of the mitochondrial myopathy were found, which was associated with a significant decrease (fro $93 \%$ to $50 \%$ ) of the mutational load of G9379A in skeletal muscle.

- Our results demonstrate the variable course of disease caused by mtDNA mutations. A possible positive outcome should be considered when counselling patients with mtDNA disorders.

anterior) respectively, were differentiated and separately counted for fibre types I and II. Immunohistochemical stains ${ }^{7}$ and activities of respiratory chain (RC) complexes I-IV were determined in skeletal muscle as described. ${ }^{8}$

\section{DNA analysis}

The G9379A mutation was originally found by sequencing the entire mitochondrial genome. ${ }^{9}$ The mutational load was quantified by PCR and RFLP in total muscle DNA of the patient's first and second muscle biopsy specimen and in DNA extracted from myoblast cells cultured from the second muscle biopsy as previously described. ${ }^{4}$

\section{RESULTS}

Histological regression of the mitochondrial myopathy

When compared with the first muscle biopsy, which showed signs of a chronic myopathy with fibre size variations, 50\% RRF, and severe generalised COX deficiency on histochemistry, ${ }^{4}$ the second muscle biopsy showed marked improvement. Signs of the myopathic process were less severe (fig 1). The average percentage of RRF remained similar (47\%), but the ragged red appearance of the fibres became much less pronounced and the lipid containing vacuoles were also less

Abbreviations: CS, citrate synthase; COX, cytochrome c oxidase; RRF, ragged red fibres 

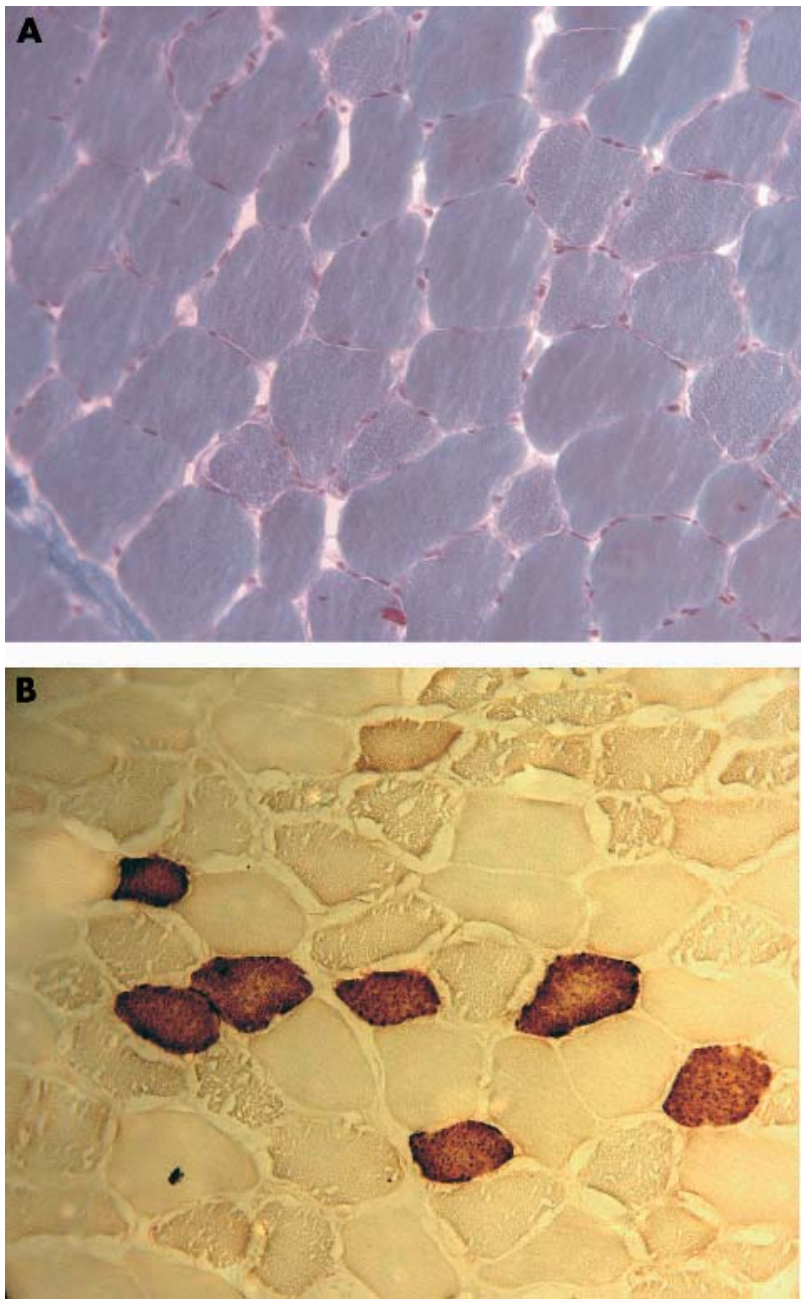

Figure 1 Signs of the myopathic process were less severe in the second muscle biopsy. The average percentage of RRFs was similar (47\%) but the ragged red appearance of the fibres became much less pronounced (A). Normal staining for COX was seen in $14 \%$ of all fibres in the second biopsy specimen (B). Vacuoles are caused by lipid accumulation.

prevalent (fig 1A). In the second biopsy specimen (fig 1B) $14 \%$ of all fibres showed normal staining for COX, a significant change compared with the almost complete absence of COX staining in the first biopsy. In the first biopsy, $48 \%$ of all fibres were type I and $52 \%$ were type II, compared with $68 \%$ and $32 \%$ respectively for the second biopsy.

\section{Biochemical measurements of RC enzymes showed increased, but still low activity of COX}

Biochemically, there was a 2.5 fold increase in the activity (units) of COX/citrate synthase (CS) in the second biopsy specimen compared with the first, but the activity remained low (table 1). The increased activity of the mitochondrial marker enzyme CS in the first biopsy, probably reflecting compensatory mechanisms, almost normalised in the second biopsy (table 1).

\section{Immunohistochemistry of skeletal muscle points to a recovery of COX II/III subunits}

In the first biopsy, immunohistochemistry showed a virtual absence of immunoreactivity of the mtDNA encoded subunits II/III compared with control muscle. ${ }^{4}$ Increased immunoreactivity in the subsarcolemmal zone due to the accumulation of mitochondria was observed. The second biopsy showed a significant recovery of subunits II/III in COX positive fibres. On serial sections, the histochemically COX negative fibres (fig 2A) showed negative staining for COX subunits II/III; however, some of these fibres stained positive for subunits Vab (fig 2B, C). The subsarcolemmal mitochondrial proliferation also became less severe.

\section{DNA analysis reveals a significant decrease in the mutational load of G9379A}

G9379A creates a stop codon (W58X) in COIII and has been identified as the causative mutation. ${ }^{4}$ Electrophoresis revealed a high rate (93\%) of the heteroplasmic G9379A point mutation in DNA extracted from the first muscle biopsy specimen, but a lower rate in the muscle DNA extracted from the second biopsy $(50 \%)$. The mutation was not present in myoblast cells of the patient cultured from the second biopsy (fig 3).

\section{DISCUSSION}

We have described a novel heteroplasmic mtDNA stop mutation (W58X) in COIII in a patient with mitochondrial myopathy. Including this patient, five cases are now reported with different pathogenic mutations of the mitochondrial encoded COIII subunit gene. ${ }^{40-13}$ Despite significant decline in COX activity in skeletal muscle (10-20\% residual activity), both clinical outcome and muscle involvement of COX III deficient patients were relatively mild. In three of the reported five patients (including ours) the mutation was found almost exclusively in skeletal muscle.

On recent examinations, our patient presented with an almost complete clinical recovery and with a significant histological improvement (table 1 ). In support of this, a marked decrease of the mutational load was observed in the second biopsy. The G9379A mutation showed a high rate $(93 \%)$ in the first muscle biopsy and was absent in blood DNA and hair follicles. ${ }^{4}$ In the second biopsy, the mutational load was 50\% and as with blood DNA and hair follicles, the mutation is absent in myoblasts. Myoblasts, also known as satellite cells, determine the regenerative capacity of skeletal muscle after injury, surgery, or neuromuscular diseases..$^{14}$ The fact that the myoblasts of our patient do not harbour the mutation would support the idea that they fuse into already existing muscle fibres and decrease the mutant/wild type ratio during regeneration as has been suggested by Shoubridge et al. ${ }^{15}$

We are aware of the fact that differences in the mutational load may occur between different muscles and even different biopsy specimens of the same muscle in the same patient. Notably, the different composition of fibre types among the two biopsied muscles may have some effect on mutational load, if the mutation were not evenly shared by type I and type II fibres. The tibialis anterior of the patient contains more type I fibres $(68 \%)$ compared with the vastus lateralis $(48 \%)$, which concurs with previous reports on a relative predominance of type I fibres in human tibialis anterior. ${ }^{56}$ However, this is unlikely to explain the drop in the mutational load (93\% in the first biopsy $v 50 \%$ in the second biopsy). Even if type II fibres carried only mutated mtDNA molecules ( $100 \%$ mutation) in both biopsies, the calculated mutational load for the second biopsy with the larger contribution of type I fibres would not be less than $89 \%$. In further support of the genetic improvement, additional analyses in our patient showed clear improvement in clinical, electrophysiological, histological, immunohistological, and biochemical parameters, as summarised in table 1 .

Changes in the mutational load in skeletal muscle of patients with different types of mtDNA mediated disorders have also been reported by other groups. For single and multiple mtDNA deletions an accumulation of mutant in 
Table 1 Summary of the clinical, histological, biochemical and genetic data of the patient at 14 and 20 years of age

\begin{tabular}{|c|c|c|}
\hline & \multicolumn{2}{|l|}{ Age (years) } \\
\hline & 14 & 20 \\
\hline Clinical presentation & $\begin{array}{l}\text { MRC scale } 4 / 5 \text { for both proximal } \\
\text { arm and leg muscles and for foot } \\
\text { dorsiflexors } \\
\text { Exercise intolerance and painful } \\
\text { muscle cramps; scapular winging }\end{array}$ & $\begin{array}{l}\text { MRC scale } 5 / 5 \text { for both proximal and } \\
\text { distal arm and leg muscles, mild difficulty } \\
\text { in heelwalking } \\
\text { No exercise intolerance, no muscle } \\
\text { cramps; mild scapular winging }\end{array}$ \\
\hline Somatic growth & $\begin{array}{l}\text { Height: 3rd-10th percentile; weight: } \\
\text { below 3rd percentile }\end{array}$ & $\begin{array}{l}\text { Height: } 50 \text { th percentile; weight: } 5 \text { th } \\
\text { percentile }\end{array}$ \\
\hline $\begin{array}{l}\text { Serum lactate (NR 0.5- } \\
2.2 \mathrm{mmol} / \mathrm{l} \text { ) }\end{array}$ & $\begin{array}{l}\text { Highly elevated: up to } 12.8 \mathrm{mmol} / \mathrm{l} \text {; } \\
\text { abnormal increase after exercise }\end{array}$ & $\begin{array}{l}\text { Mildly elevated: } 2.9 \mathrm{mmol} / \mathrm{l} \text {; normal } \\
\text { increase after exercise }\end{array}$ \\
\hline Electromyography & $\begin{array}{l}\text { Myopathic changes, polyphasic, low } \\
\text { amplitude action potentials in deltoid } \\
\text { and quadriceps muscles }\end{array}$ & $\begin{array}{l}\text { Normal in deltoid and quadriceps, but } \\
\text { very mild increase in spontaneous activity } \\
\text { in the right tibialis anterior muscle }\end{array}$ \\
\hline Muscle histology & $\begin{array}{l}\text { Chronic myopathy; } 50 \% \text { ragged red } \\
\text { fibres; severe lipid accumulation; } \\
\text { severe COX defect in all fibres }\end{array}$ & $\begin{array}{l}\text { Mild myopathic changes; } 47 \% \text { ragged red } \\
\text { fibres; milder lipid accumulation; } 14 \% \\
\text { COX positive fibres }\end{array}$ \\
\hline Immunohistochemistry & $\begin{array}{l}\text { Virtual absence of COX II/III but } \\
\text { normal staining for COX IV in all } \\
\text { fibres }\end{array}$ & $\begin{array}{l}\text { COX positive fibres were positive for COX } \\
\text { II/III, IV, and Vab, but some of the COX } \\
\text { negative fibres were also positive for COX } \\
\text { IV and Vab }\end{array}$ \\
\hline COX (NR 0.90-4.70) & $0.03 \mathrm{U} / \mathrm{U} C S$ & $0.08 \mathrm{U} / \mathrm{U}$ \\
\hline CS: $45-105 \mathrm{U} / \mathrm{gNCP})$ & $256 \mathrm{U} / \mathrm{g} \mathrm{NCP}$ & $136 \mathrm{U} / \mathrm{g} \mathrm{NCP}$ \\
\hline Rate of mutant mtDNA & $\begin{array}{l}93 \% \text { mutant mtDNA in muscle; } \\
0 \% \text { in hair follicles; } 0 \% \text { in blood }\end{array}$ & $\begin{array}{l}50 \% \text { mutant mtDNA in muscle; } 0 \% \text { mutant } \\
\text { in myoblasts }\end{array}$ \\
\hline
\end{tabular}

skeletal muscle was shown with time, ${ }^{316}$ but there are few data known about mtDNA point mutations. In a previous study, ${ }^{15}$ one patient with a point mutation in tRNA ${ }^{\text {Leu (CUN) }}$ presented a remarkable increase $(33.4 \%)$ in the ratio of the wild type genome after 11 days of concentrated exercise (from $11.8 \%$ to $48.4 \%$ ). Physiological, biochemical, and genetic testing of patients carrying different mtDNA mutations in skeletal muscle were previously performed before and after 14 weeks of aerobic conditioning training. ${ }^{17}{ }^{18}$ There was a biochemical improvement observed in the activity of respiratory chain complexes and in oxygen utilisation; however, the proportion of wild type mtDNA was unchanged or slightly decreased, suggesting a trend toward preferential proliferation of mutant genomes. These results imply a training induced mitochondrial proliferation that might result in changes of the ratio of mutant to wild type mtDNA. Another example of a re-examination of skeletal muscle concerned a patient with the recently reported $15 \mathrm{bp}$ microdeletion in COIII. The deletion was detected with a high rate of heteroplasmy in skeletal muscle $(92 \%)$ and a very low rate in blood $(0.7 \%)$, and except for episodes of recurrent myoglobinuria the muscle strength of the patient was normal. ${ }^{11}$ This patient was included in the studies of Taivassalo et a l17 $18^{18}$ and a second biopsy was performed 5 years later. Like our results, there was a significant difference in the mutational load compared with the original publication (from $92 \%$ to $36 \%$ ). However the mutational load in repeated muscle biopsies of other patients of Taivassalo et $a l^{17}{ }^{18}$ carrying different types of mtDNA mutations showed minor differences only. As we do not have enough follow up data about other cases, we cannot predict how often spontaneous recovery occurs in patients with different types of mtDNA mutations. In both our patient and the patient carrying the 15 bp microdeletion and showing decrease in the mutational load, the mutation was located to COIII. Whether or not this phenomenon is characteristic for mutations in COIII needs to be confirmed in a larger number of cases.

The improvement of the biochemical COX activity and the histological staining of skeletal muscle for COX partly resembles another disease entity, benign infantile COX deficiency syndrome. This rare syndrome is characterised by severe muscular hypotonia, generalised weakness, and lactic acidosis in early infantile period, and if the patient survives this stage, complete or almost complete recovery occurs within 1-2 years. ${ }^{19} 20$ The mode of inheritance and the mechanism of the reversibility are still unknown. ${ }^{21}$ The presence of mitochondrial abnormalities and RRF in this syndrome has been repeatedly confirmed, ${ }^{19} 2022$ suggesting a role of mtDNA mutations in the pathomechanism; however, no mutation in the mtDNA has been found so far in these patients.

What might account for the improvement of the muscular symptoms in our patient with a stop mutation in COIII? Functional studies on cybrids containing the $15 \mathrm{bp}$ microdeletion in COIII have shown that only homoplasmic mutants fail to assemble the COX holoenzyme and even 3\% wild type COIII can have a marked positive effect on the functioning of the respiratory chain. ${ }^{23}$ The decrease in the mutational load of W58X in our patient might be responsible for the clinical improvement, and even the small increase in COX activity might result in a relatively good muscle energy supply. MtDNA wild type containing myoblasts may fuse into existing muscle fibres over time and positively influence the rate of mutant in skeletal muscle. This mechanism may explain the change of the mutational load and indirectly the positive clinical outcome in our patient.

In summary, a remarkable clinical and histological improvement of mitochondrial myopathy together with a decrease in the mutational load was observed in a patient carrying a stop mutation in the mitochondrially encoded COXIII subunit gene. Our results demonstrate again the variable course of diseases caused by mtDNA mutations and a possible positive outcome should be considered in counseling patients with mtDNA mediated disorders.

\section{ACKNOWLEDGEMENTS}

The excellent technical assistance of A Zimmermann, S Galuschka, and E Schmidtmeyer and the clinical work of Dr C Schröder and Dr M Sievers are gratefully acknowledged. This work is supported by 

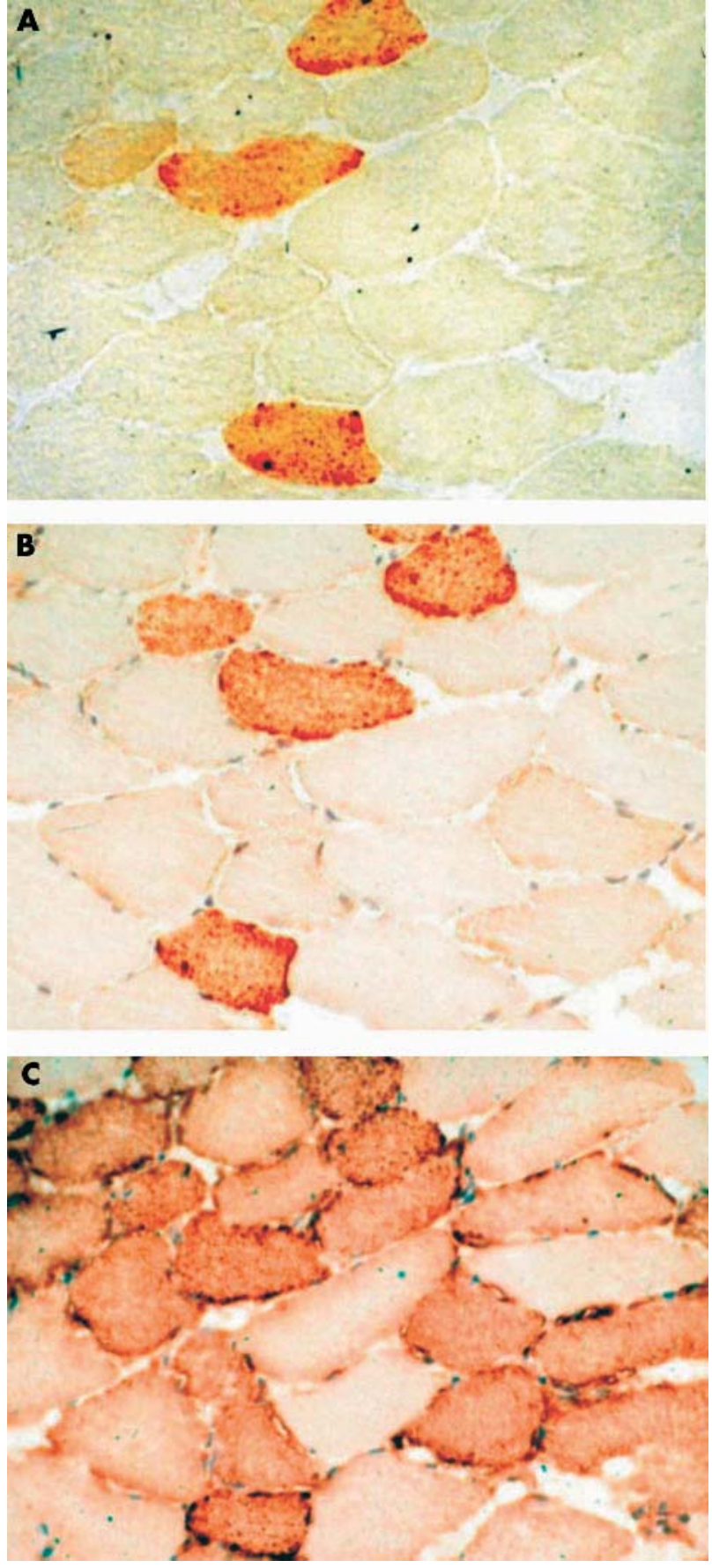

Figure 2 On serial sections of the second muscle biopsy, histochemical stain for COX (A), and immunohistochemistry for COX II/III (B) and Vab (C) subunits were performed. COX staining was positive for $14 \%$ of all fibres (A). There was a significant recovery of subunits II/III in COX positive fibres (B). The histochemically COX negative fibres showed negative staining for $\mathrm{COX}$ subunits II/III; however, some of these fibres stained positive for subunits Vab (fig 2B, C).

grants from the Deutsche Forschungsgemeinschaft Ja802/2-1 (M Jaksch) and the Ernst and Berta Grimmke Stiftung (M Jaksch, R Horváth). Human myoblast cultures were obtained from the Muscle Tissue Culture Collection (Friedrich Baur Institute, Munich, Germany), part of the German network on muscular dystrophies (MD-NET, service structure Sl, 01GM0302) funded by the BMBF (Bonn, Germany), partner of Eurobiobank (Eurordis; scientific coordinator: Dr C Jaeger, Paris, France), funded by the EC within the Fifth Framework (QLRT-2001-02769).

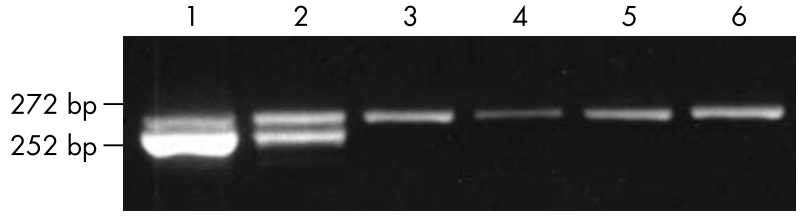

Figure 3 RFLP analysis of the heteroplasmic G9379A point mutation revealed a high rate (93\%) in DNA extracted from the first muscle biopsy specimen (lane 1), but a lower rate (50\%) in the muscle DNA extracted from the second biopsy (lane 2). The mutation was not present in myoblast cells of the patient cultured from the second biopsy (lane 3), or in hair follicles (lane 4) and blood DNA of the patient (lane 5) and his mother (lane 6).

\section{Authors' affiliations}

R Horváth, M Jaksch, Metabolic Disease Center Munich-Schwabing, Institutes of Clinical Chemistry, Molecular Diagnostics and Mitochondrial Genetics; Academic Hospital Schwabing, Munich, Germany

H Lochmüller, B G Schoser, D Pongratz, Friedrich Baur Institute, Department of Neurology, Ludwig Maximilians University, Munich, Germany

M Hoeltzenbein, Max Planck Institute for Molecular Genetics, Berlin, Germany

J Müller-Höcker, Institute of Pathology, Ludwig Maximilians University, Munich, Germany

Conflict of interest: none declared

Correspondence to: Dr. M Jaksch, Metabolic Disease Center MunichSchwabing, Institutes of Clinical Chemistry, Molecular Diagnostics and Mitochondrial Genetics, Academic Hospital Schwabing, Kölner Platz 1, 80804 München, Germany; michaela.jaksch@|rz.uni-muenchen.de

Revised version received 17 November 2003

Accepted for publication 19 November 2003

\section{REFERENCES}

1 DiMauro S, Schon EA. Mitochondrial respiratory-chain diseases. NEngl J Med 2003;348:2656-68.

2 Chinnery PF, Howel D, Turnbull DM, Johnson MA. Clinical progression of mitochondrial myopathy is associated with the random accumulation of cytochrome c oxidase negative skeletal muscle fibres. I Neurol Sci 2003;211:63-6.

3 Larsson NG, Holme E, Kristiansson B, Oldfors A, Tulinius M. Progressive increase of the mutated mitochondrial DNA fraction in Kearns-Sayre syndrome. Pediatr Res 1990;28:131-6.

4 Horvath R, Scharfe C, Hoeltzenbein M, Do BH, Schroder C, Warzok R, Vogelgesang S, Lochmuller H, Muller-Hocker J, Gerbitz KD, Oefner PJ, Jaksch M. Childhood onset mitochondrial myopathy and lactic acidosis caused by a stop mutation in the mitochondrial cytochrome c oxidase III gene. J Med Genet 2002;39:812-16.

5 Dubowitz V. Muscle biopsy: a practical approach, 2nd edn. London: Bailliere, Tindall and Cox, 1985

6 Johnson MA, Polgar J, Weightman D, Appleton D. Data on the distribution of fibre types in thirty-six human muscles. An autopsy study. J Neurol Sci 1973;18:111-29.

7 Müller-Höcker J, Droste M, Kadenbach B, Pongratz D, Hübner G. Fatal mitochondrial myopathy with cytochrome-c-oxidase deficiency and subunitrestricted reduction of enzyme protein in two siblings: an autopsyimmunocytochemical study. Hum Pathol 1989;20:666-72.

8 Fischer JC, Ruitenbeek W, Gabreels FJ, Janssen AJ, Renier WO, Sengers RC, Stadhouders AM, ter Laak HJ, Trijbels JM, Veerkamp JH. A mitochondrial encephalomyopathy: the first case with an established defect at the level of coenzyme Q. Eur J Pediatr 1986;144:441-4.

9 Andrews RM, Kubacka I, Chinnery PF, Lightowlers RN, Turnbull DM, Howell N. Reanalysis and revision of the Cambridge reference sequence for human mitochondrial DNA. Nat Genet 1999;23:147.

10 Hanna MG, Nelson IP, Rahman S, Lane RJ, Land J, Heales S, Cooper MJ, Schapira AH, Morgan-Hughes JA, Wood NW. Cytochrome c oxidase deficiency associated with the first stop-codon point mutation in human mtDNA. Am J Hum Genet 1998;63:29-36.

11 Keightley JA, Hoffbuhr KC, Burton MD, Salas VM, Johnston WS, Penn AM Buist NR, Kennaway NG. A microdeletion in cytochrome c oxidase (COX) subunit III associated with COX deficiency and recurrent myoglobinuria. Nat Genet 1996;12:410-16.

12 Manfredi G, Schon EA, Moraes CT, Bonilla E, Berry GT, Sladky JT, DiMauro S A new mutation associated with MELAS is located in a mitochondrial DNA polypeptide-coding gene. Neuromuscul Disord 1995;5:391-8.

13 Tiranti V, Corona P, Greco M, Taanman JW, Carrara F, Lamantea E, Niitmans L, Uziel G, Zeviani M. A novel frameshift mutation of the mtDNA 
COIII gene leads to impaired assembly of cytochrome c oxidase in a patient affected by Leigh-like syndrome. Hum Mol Genet 2000;9:2733-42.

14 Renault V, Thorne LE, Eriksson PO, Butler-Browne G, Mouly V. Regenerative potential of human skeletal muscle during aging. Aging Cell 2002;1:132-9.

15 Taivassalo T, Fu K, Johns T, Arnold D, Karpati G, Shoubridge EA. Gene shiffing: a novel therapy for mitochondrial myopathy. Hum Mol Genet 1999;8:1047-52

16 Hirano M, Marti R, Ferreiro-Barros C, Vila MR, Tadesse S, Nishigaki Y, Nishino I, Vu TH. Defects of intergenomic communication: autosomal disorders that cause multiple deletions and depletion of mitochondrial DNA. Semin Cell Dev Biol 2001;12:417-27.

17 Taivassalo T, Shoubridge EA, Chen J, Kennaway NG, DiMauro S, Arnold DL, Haller RG. Aerobic conditioning in patients with mitochondrial myopathies: physiological, biochemical, and genetic effects. Ann Neurol 2001:50:133-41.

18 Taivassalo T, Jensen TD, Kennaway N, DiMauro S, Vissing J, Haller RG. The spectrum of exercise tolerance in mitochondrial myopathies: a study of 40 patients. Brain 2003;126:413-23.
19 DiMauro S, Nicholson JF, Hays AP, Eastwood AB, Papadimitriou A, Koenigsberger R, DeVivo DC. Benign infantile mitochondrial myopathy due to reversible cyłochrome c oxidase deficiency. Ann Neurol 1983;14:226-34

20 Salo MK, Rapola J, Somer H, Pihko H, Koivikko M, Tritschler HJ, DiMauro S Reversible mitochondrial myopathy with cytochrome $\mathrm{c}$ oxidase deficiency. Arch Dis Child 1992;67:1033-5.

21 Robinson BH. Human cytochrome oxidase deficiency. Pediatr Res 2000;48:581-5.

22 Wada $\mathrm{H}$, Woo M, Nishio $\mathrm{H}$, Nagaki S, Yanagawa H, Imamura A, Yokoyama S, Ohbayashi C, Matsuo M, Itoh H, Nakamura H. Vascular involvement in benign infantile mitochondrial myopathy caused by reversible cytochrome c oxidase deficiency. Brain Dev 1996;18:263-8.

23 Hoffbuhr KC, Davidson E, Filiano BA, Davidson M, Kennaway NG ,

King MP. A pathogenic 15-base pair deletion in mitochondrial

DNA-encoded cytochrome $\mathrm{c}$ oxidase subunit III results in the absence of functional cytochrome c oxidase. J Biol Chem 2000;275:13994-14003. 